\title{
PENERAPAN PERSONAL HIGIENE KARYAWANHOME INDUSTRY KERUPUK DI DESA SINDANG KECAMATAN SINDANG KABUPATEN INDRAMAYU
}

\author{
Ade Kristiana ${ }^{1}$, Tati Setiawati², Rita Patriasih ${ }^{3}$ \\ Program Studi Pendidikan Tata Boga, Departemen Pendidikan Kesejahteraan \\ Keluarga, Fakultas Pendidikan Teknologi dan Kejuruan, Universitas Pendididkan \\ Indonesia
}

Adekristiana12@gmail.com

\begin{abstract}
Abstrak: Personal higiene dalam industri makanan merupakan salah satu hal penting yang harus diterapkan. Hal ini terkait dengan penjaminan aspek keamanan produk makanan dari terjadinya kontaminasi silang. Makanan menjadi aman untuk dikonsumsi dalam arti bebas dari hal-hal yang dapat membahayakan, merugikan dan terhindar dari kerusakan. Berdasarkan studi pendahuluan di desa Sindang Kabupaten Indramayu terdapat home industry kerupuk yang belum sepenuhnya menerapkan personal higiene dengan baik. Peneliti ingin mengetahui bagaimana penerapan personal higiene pada home industry kerupuk secara keseluruhan. Tujuan umum dalam penelitian ini adalah untuk memperoleh informasi mengenai penerapan personal higiene karyawan home industry kerupuk di desa Sindang kecamatan Sindang kabupaten Indramayu. Metode penelitian yang digunakan ialah deskriptif kuantitatif. Teknik pengumpulan data yang digunakan yaitu kuesioner dengan metode observasi. Hasil penelitian menunjukan bahwa sikap personal higiene karyawan yang meliputi kebersihan rambut, hidung, mulut dan gigi, tangan dan jari tangan, badan, serta pakaian kerja pada penerapan personal higiene saat bekerja masuk pada kategori sangat baik. Perilaku personal higiene karyawan saat bekerja masuk pada kategori tidak diterapkan. Rekomendasi penelitian ini perlu ditingkatkan kembali mengenai penerapan personal higiene karyawan saat bekerja dan untuk pengelola home industry diharapkan dapat memberikan pelatihan dan penyuluhan mengenai personal higiene kepada karyawan agar penerapan personal higiene dapat diterapkan dengan baik.
\end{abstract}

Kata Kunci: home industry kerupuk, personal higiene.

\section{PENDAHULUAN}

Home Industry merupakan perusahaan yang memiliki tempat usaha di tempat tinggal dengan peralatan pengolahan pangan manual hingga semi otomatis. Personal higiene dalam industri makanan merupakan salah satu hal penting yang harus diterapkan. Hal ini terkait dengan penjaminan aspek keamanan produk makanan dari terjadinya kontaminasi silang. Makanan menjadi aman untuk dikonsumsi dalam arti bebas dari halhal yang dapat membahayakan, merugikan dan terhindar dari kerusakan.

Kontaminasi terjadi karena kurang memperhatikan personal higiene dalam mengolah makanan seperti mencuci tangan sebelum menjamah makanan, memelihara kebersihan badan, rambut, telinga, hidung, mulut, tangan, serta pemeliharaan kesehatan.

Makanan yang aman yaitu makanan yang memenuhi syarat sanitasi higiene dan higiene personal. Salah satu pertimbangan konsumen dalam memilih makanan adalah karena faktor keamanan makanan (Rudi dan Koesyanto, 2017).

Personal higiene merupakan segala sesuatu yang meliputi kesehatan diri. Higiene merupakan ilmu yang mengajarkan cara-cara untuk 
mempertahankan kesehatan jasmani, rohani, dan sosial untuk mencapai tingkat kesejahteraan yang lebih tinggi (Prastowo, 2014, hlm 3). Personal higiene adalah suatu kegiatan atau aktivitas seseorang yang dilakukan secara terus menerus untuk memelihara kebersihan dan kesehatan diri (Wulandari, dkk, 2015, hlm 66).

Penerapan personal higiene yang tinggi dapat menentukan hasil akhir dari makanan yang diolah apakah makanan tersebut aman untuk dikonsumsi, aman disini artinya bebas dari hal-hal yang dapat membahayakan, merugikan dan bebas dari kerusakan, karena penyakit bawaan makanan adalah suatu permasalahan kesehatan masyarakat yang banyak terjadi di era modern ini (WHO, 2005).

Berdasarkan studi pendahuluan di desa Sindang Kabupaten Indramayu terdapat home industry kerupuk yang belum sepenuhnya menerapkan personal higiene dengan baik. Hal tersebut dilihat dari karyawan yang tidak menggunakan baju pada saat mengemas kerupuk yang sudah digoreng, tidak menggunakan sarung tangan pada saat pengemasan produk kerupuk.

Kerupuk merupakan suatu jenis makanan ringan yang sudah dikenal dan di gemari oleh masyarakat Indonesia. Kerupuk disukai oleh banyak kalangan mulai dari anak-anak hingga orang dewasa. Kerupuk memiliki tekstur yang renyah dan garing yang dapat dikonsumsi sebagai makanan selingan maupun sebagai variasi dalam lauk pauk (Koswara, 2009). Komoditi pedagang kerupuk termasuk jenis industri yang berpotensi cukup baik. Kerupak menjadi salah satu makanan yang banyak diminati oleh masyarakat namun masih terdapat beberapa kekurangan dalam pengolahan dan keamanan pangannya, dimana kerupuk yang dihasilkan akan di konsumsi oleh masyarakat dan dapat menimbulkan masalah kesehatan pada konsumen.

Penelitian ini bertujuan untuk mengetahui penerapan personal higiene karyawan home industry kerupuk di desa Sindang Kecamatan Sindang Kabupaten Indramayu.

\section{METODE}

Desain yang digunakan pada penelitian ini adalah deskriptif kuantitatif. Penelitian dilakukan dari bulan April 2019 - Desember 2019. Teknik pengumpulan responden dalam penelitian ini menggunakan sensus sebanyak 10 orang responden karyawan home industry kerupuk. Teknik pengumpulan data yang digunakan yaitu kuesioner dengan metode observasi.

\section{HASIL DAN PEMBAHASAN Sikap Personal Higiene Karyawan Home Industry Kerupuk}

Sikap personal higiene karyawan pada penelitian ini meliputi kebersihan rambut, hidung, mulut dan gigi, tangan dan jari tangan, badan, serta pakaian kerja. Adapaun sikap personal higiene karyawan home industry kerupuk seperti yang disajikan pada Tabel 1 .

Tabel 1. Sikap Personal Higiene Karyawan Saat Bekerja

\begin{tabular}{|c|c|c|c|}
\hline No. & $\begin{array}{c}\text { Total } \\
\text { Skor }\end{array}$ & $\%$ & Kriteria \\
\hline 1 & 45 & 90 & Sangat Baik \\
\hline 2 & 46 & 92 & Sangat Baik \\
\hline 3 & 46 & 92 & Sangat Baik \\
\hline 4 & 43 & 86 & Sangat Baik \\
\hline 5 & 45 & 90 & Sangat Baik \\
\hline 6 & 44 & 88 & Sangat Baik \\
\hline 7 & 41 & 82 & Sangat Baik \\
\hline 8 & 42 & 84 & Sangat Baik \\
\hline 9 & 37 & 74 & Sangat Baik \\
\hline
\end{tabular}




\begin{tabular}{|c|c|c|r|}
\hline 10 & 42 & 84 & Sangat Baik \\
\hline \multicolumn{2}{|c|}{ Rata- rata } & $\mathbf{8 6 , 2}$ & Sangat Baik \\
\hline
\end{tabular}

Sikap Personal Higiene Karyawan Berkaitan Dengan Pemeriksaan Kesehatan masuk pada kategori sangat baik (90\%). Hal tersebut sejalan dengan sikap personal higiene karyawan didasarkan pada poin syarat higiene karyawan yang baik tercantum dalam Peraturan Kepala Badan Pengawas Obat Dan Makanan Republik Indonesia Nomor Hk.03.1.23.04.12.2206 Tahun 2012

Tentang Cara Produksi Pangan Yang Baik Untuk Industri Rumah Tangga yang terdiri dari: (1) kesehatan karyawan, (2) kebersihan karyawan dan (3) kebiasaan karyawan. Berdasarkan hasil pengamatan pada penelitian ini tidak ditemukan karyawan yang sakit pada saat bekerja.

Sikap Personal Higiene Karyawan Berkaitan Dengan Kebersihan Rambut masuk pada kategori sangat baik (92\%). Hal tersebut sejalan dengan pendapat Prastowo (2014, hlm. 6) rambut sebaiknya dicukur pendek untuk karyawan laki - laki dan pencucian rambut sebaiknya dilaksanakan secara teratur serta karyawan diharuskan menggunakan tutup kepala (hair cap/ hair net). Berdasarkan hasil pengamatan pada saat penelitian karyawan laki - laki mencukur pendek rambut, dan untuk perempuan menggunakan kerudung. Akan tetapi karyawan laki - laki tidak menggunakan penutup kepala (hair cap/ hair net). Dengan hasil yang telah diperoleh tersebut, dapat diartikan bahwa penerapan personal higiene perlu ditingkatkan lagi. Peningkatan tersebut terfokus pada penggunaan kelengkapan pakaian kerja seperti celemek, penutup kepala, sarung tangan, dan masker.
Sikap personal higiene karyawan berkaitan dengan kebersihan tangan dan jari tangan masuk pada kategori sangat baik. Hal tersebut sejalan dengan sikap personal higiene karyawan berkaitan dengan kebersihan tangan dan jari tangan didasarkan pada poin syarat higiene karyawan yang baik tercantum dalam Peraturan Kepala Badan Pengawas Obat Dan Makanan Republik Indonesia Nomor Hk.03.1.23.04.12.2206 Tahun 2012 Tentang Cara Produksi Pangan Yang Baik Untuk Industri Rumah Tangga yaitu Karyawan yang menangani pangan harus menutup luka di anggota tubuh dengan perban khusus luka. Karyawan harus selalu mencuci tangan dengan sabun sebelum memulai kegiatan mengolah pangan, sesudah menangani bahan mentah, atau bahan / alat yang kotor, dan sesudah ke luar dari toilet / jamban.

Sikap Personal Higiene Karyawan Berkaitan Dengan Kesehatan Mulut dan Gigi masuk pada kategori sangat baik (90\%). Hal tersebut sejalan dengan sikap personal higiene karyawan berkaitan dengan kebersihan mulut dan gigi didasarkan pada poin syarat higiene karyawan yang baik tercantum dalam Peraturan Kepala Badan Pengawas Obat Dan Makanan Republik Indonesia Nomor Hk.03.1.23.04.12.2206 Tahun 2012 Tentang Cara Produksi Pangan Yang Baik Untuk Industri Rumah Tangga yaitu Karyawan yang bekerja sebaiknya tidak makan dan minum, merokok, meludah, bersin atau batuk ke arah pangan atau melakukan tindakan lain di tempat produksi yang dapat mengakibatkan pencemaran produk pangan. Oleh karena itu sebaiknya karyawan lebih memperhatikan lagi penerapan personal higiene dan kebiasaan pada saat bekerja. 
Sikap personal higiene karyawan berkaitan dengan kebersihan hidung masuk pada kategori sangat baik. Hal tersebut sejalan dengan sikap personal higiene karyawan berkaitan dengan kebersihan hidung didasarkan pada poin syarat higiene karyawan yang baik tercantum dalam Peraturan Kepala Badan Pengawas Obat Dan Makanan Republik Indonesia Nomor Hk.03.1.23.04.12.2206 Tahun 2012 Tentang Cara Produksi Pangan Yang Baik Untuk Industri Rumah Tangga yaitu Karyawan yang menangani pangan seharusnya mengenakan pakaian kerja yang bersih. Pakaian kerja dapat berupa celemek, penutup kepala, sarung tangan, masker dan / atau sepatu kerja. Dengan hasil yang telah diproleh tersebut, dapat diartikan bahwa penerapan personal higiene perlu ditingkatkan. Peningkatan tersebut terfokus pada kebersihan dan penggunaan pakaian kerja lengkap seperti masker pada saat bekerja.

Sikap Personal Higiene Karyawan Berkaitan Dengan Kebersihan Pakaian Kerja masuk pada kategori baik (74\%). Hal tersebut sejalan dengan Sikap personal higiene karyawan didasarkan pada poin syarat higiene karyawan yang baik tercantum dalam Peraturan Kepala Badan Pengawas Obat Dan Makanan Republik Indonesia Nomor Hk.03.1.23.04.12.2206 Tahun 2012 Tentang Cara Produksi Pangan Yang Baik Untuk Industri Rumah Tangga yaitu Karyawan yang menangani pangan seharusnya mengenakan pakaian kerja yang bersih. Pakaian kerja dapat berupa celemek, penutup kepala, sarung tangan, masker dan / atau sepatu kerja.

Sikap Personal Higiene Karyawan Berkaitan Dengan Kebersihan Badan masuk pada kategori sangat baik (84\%). Hal tersebut sejalan dengan
Sikap personal higiene karyawan didasarkan pada poin syarat higiene karyawan yang baik tercantum dalam Peraturan Kepala Badan Pengawas Obat Dan Makanan Republik Indonesia Nomor Hk.03.1.23.04.12.2206 Tahun 2012 Tentang Cara Produksi Pangan Yang Baik Untuk Industri Rumah Tangga yang terdiri dari: (1) kesehatan karyawan, (2) kebersihan karyawan dan (3) kebiasaan karyawan.

\section{Perilaku Personal Higiene Karyawan \\ Home Industry Kerupuk Saat \\ Bekerja}

Perilaku personal higiene karyawan home industry kerupuk disajikan dalam tabel 2.

Tabel 2. Perilaku Personal Higiene Karyawan Saat Bekerja

\begin{tabular}{|c|r|c|c|}
\hline \multirow{2}{*}{ No. } & \multicolumn{2}{|c|}{$\begin{array}{c}\text { Perilaku } \\
\text { Responden }\end{array}$} & \multirow{2}{*}{$\begin{array}{c}\% \\
\text { Benar }\end{array}$} \\
\cline { 2 - 3 } & \multicolumn{1}{|c|}{ Y } & \multicolumn{1}{|c|}{ T } & \\
\hline 1 & 6 & 4 & $60 \%$ \\
\hline 2 & 0 & 10 & $0 \%$ \\
\hline 3 & 9 & 1 & $90 \%$ \\
\hline 4 & 4 & 6 & $40 \%$ \\
\hline 5 & 0 & 10 & $0 \%$ \\
\hline 6 & 10 & 0 & $100 \%$ \\
\hline 7 & 2 & 8 & $20 \%$ \\
\hline 8 & 9 & 1 & $90 \%$ \\
\hline 9 & 0 & 10 & $0 \%$ \\
\hline 10 & 2 & 8 & $20 \%$ \\
\hline 11 & 0 & 10 & $0 \%$ \\
\hline 12 & 5 & 5 & $50 \%$ \\
\hline \multicolumn{3}{|c}{ Rata - rata } & $39 \%$ \\
\hline
\end{tabular}

Berdasarkan hasil data yang diperoleh, telah didapatkan mengenai Perilaku personal higiene karyawan saat bekerja. Persentase data tersebut menunjukan kurang dari setengahnya (39\%) penerapan personal higiene masuk dalam kategori tidak diterapkan Perilaku atau kebiasaan karyawan 
tercantum dalam Peraturan Kepala Badan Pengawas Obat Dan Makanan Republik Indonesia Nomor Hk.03.1.23.04.12.2206 Tahun 2012 Tentang Cara Produksi Pangan Yang Baik Untuk Industri Rumah Tangga yang terdiri dari: (1) kesehatan karyawan, (2) kebersihan karyawan dan (3) kebiasaan karyawan. Dengan hasil yang telah diperoleh tersebut, dapat diartikan bahwa penerapan personal higiene perlu ditingkatkan lagi. Peningkatan tersebut terfokus pada perilaku keryawan yang masih belum memperhatikan personal higiene saat bekerja seperti tidak menggunakan alas kaki saat bekerja, tidak menggunakan sepatu yang tertutup hanya menggunakan sandal jepit, tidak menggunakan celemek dan pakaian kerja yang lengkap hanya menggunakan baju pendek dan celana pendek, tidak menggunakan sarung tangan saat mengemas kerupuk yang sudah matang, mengobrol dengan karyawan lainnya saat mengolah kerupuk, tidak memelihara kuku dengan baik ada beberapa karyawan yang memiliki kuku kotor dan panjang, menggunakan perhiasan (cincin bermata dan gelang tangan dari plastik), dan ada karyawan yang merokok pada saat mengemas kerupuk yang sudah matang. Menurut peraturan kepala BPOM (2012, No.HK:CPPB IRT) kesehatan dan higiene karyawan yang baik dapat menjamin bahwa karyawan yang kontak langsung maupun tidak langsung dengan pangan tidak menjadi sumber pencemaran. Oleh karena itu, penerapan personal higiene menjadi salah satu syarat penting pada saat mengolah makanan.

\section{KESIMPULAN}

Sikap personal higiene karyawan yang meliputi kebersihan rambut, hidung, mulut dan gigi, tangan dan jari tangan, badan, serta pakaian kerja pada penerapan personal higiene saat bekerja masuk pada kategori sangat baik.

Perilaku personal higiene karyawan saat bekerja masuk dalam kategori tidak diterapkan. Hal tersebut dapat dilihat dari karyawan yang masih menerapkan personal higiene seperti mencuci tangan sebelum melakukan pekerjaan mengolah kerupuk namun masih belum menggunakan sabun, mencukur pendek rambut namun tidak menggunakan penutup kepala, memotong kuku hingga pendek, dan mengenakan pakaian kerja pada proses pengolahan kerupuk masih harus ditingkatkan.

\section{REKOMENDASI}

Bagi Pengelola home industry diharapkan dapat memberikan pelatihan dan penyuluhan mengenai personal higiene kepada karyawan agar penerapan personal higiene dapat diterapkan dengan baik.

Bagi peneliti selanjutnya diharapkan dapat melakukan penelitian lebih lanjut mengenai penerapan personal higiene diberbagai jenis home industry kerupuk dengan sampel yang lebih besar sehingga dapat menjadi pembanding mengenai personal higiene yang diterapkan oleh setiap home industry.

\section{REFERENSI}

Badan Pengawas Obat Dan Makanan. (2012). Cara Produksi Pangan Yang Baik Untuk Industri Rumah Tangga. Badan POM, Jakarta.

Chairunnisa, dkk. (2014). Pendapat Supervisor Tentang Penerapan Sanitasi Higiene Oleh Mahasiswa Pada Pelaksanaan Praktek Industri. Media Pendidikan, Gizi Dan Kuliner. 
Vol.3, No.1, November 2014.

Erfianto, Rudi dan Herry, Koesyanto. (2017). Hygiene Personal Pada Penjual Nasi Kucing. Higeia: journal of public heakth research anddevelopment.

http://journal.unnes.ac.id/sju/ind ex. php/higeia

Koswara, Sutrisno. (2009). Pengolahan Aneka Kerupuk. Diakses dari ebookpangan.com

Miranti A. Edinda, dkk. (2016). Hubungan Pengetahuan Dengan Sikap Dan Higiene Perorangan (Personal Hygiene) Penjamah Makanan Pada Penyelenggaraan Makanan Asrama Putri. Media Gizi Indonesia, Vol. 11 No. 2 JuliDesenber 2016: hlm. 120-126.
Prastowo, Ichwan. (2014). Hotel Hygiene dan sanitation. Yogyakarta: Deepublish.

Sitepu L, Eka. (2015). Analisis Personal Hygiene Pada Penjual Makanan Tradisional GadoGado Di Kelurahan Pisangan, Cempaka Putih Dan Cirendeu Ciputat Timur Tahun 2015. (Skripsi). Universitas Islam Negeri (UIN) Syarif Hidayatullah, Jakarta.

Wulandari, R, dkk. (2015). Pembahasan Perilaku Personal Higiene Oleh Ibu Kepada Balita (Usia 3-5 Tahun) Dikelurahan Derwati. Media Pendidikan, Gizi Dan Kuliner. Vol. 4, No.1, April 2015. 